\title{
Adherence to statin treatment and associated factors in female users from the Unified Health System (SUS)
}

\author{
ADERÊNCIA AO TRATAMENTO POR ESTATINAS E FATORES ASSOCIADOS EM \\ USUÁRIAS DO SISTEMA ÚNICO DE SAÚDE
}

\section{ADHERENCIA AL TRATAMIENTO CON ESTATINAS Y FACTORES ASOCIADOS EN USUARIAS DEL SISTEMA UNICO DE SALUD DE BRASIL}

\section{Mariana Rotta Bonfim ${ }^{1}$, Arina Hansen², Bruna Camilo Turi' ${ }^{1}$, Gabriel de Souza Zanini", Acary Souza Bulle Oliveira ${ }^{4}$, Sandra Lia do Amaral ${ }^{5}$, Henrique Luiz Monteiro ${ }^{6}$}

\begin{abstract}
Objective: To identify the adherence rate of a statin treatment and possible related factors in female users from the Unified Health System. Method: Seventy-one women were evaluated ( $64.2 \pm 11.0$ years) regarding the socio-economic level, comorbidities, current medications, level of physical activity, self-report of muscular pain, adherence to the medical prescription, body composition and biochemical profile. The data were analyzed as frequencies, Chi-Squared test, and Mann Whitney test $(p<0.05)$. Results: $15.5 \%$ of women did not adhere to the medical prescription for the statin treatment, whose had less comorbidities $(p=0.01)$, consumed less quantities of medications $(p=0.00)$, and tended to be younger $(p=0.06)$. Those patients also presented higher values of lipid profile (CT: $p=0.01$; LDL-c: $p=0.02$ ). Musculoskeletal complains were not associated to the adherence rate to the medication. Conclusion: The associated factors to adherence of dyslipidemic women to statin medical prescription were age, quantity of comorbidities and quantity of current medication.
\end{abstract}

\section{DESCRIPTORS}

Hydroxymethylglutaryl-CoA Reductase Inhibitors

Dyslipidemias

Health profile

Medication adherence

Public health

\section{RESUMO}

Objetivo: Identificar a taxa de aderência ao tratamento por estatinas e os possíveis fatores relacionados em usuárias do Sistema Único de Saúde. Método: Foram avaliadas 71 mulheres $(64,2 \pm 11,0$ anos) quanto ao nível socioeconômico, comorbidades, medicamentos em uso, nível de atividade física, autorrelato de dor muscular, aderência à prescrição médica, composição corporal e perfil bioquímico. Os dados foram submetidos à análise de frequência, teste de Qui-quadrado e teste de Mann Whitney $(p<0,05)$. Resultados: $15,5 \%$ das muIheres não aderiram à prescrição médica para o tratamento com estatinas, as quais possuíam menos comorbidades $(p=0,01)$, consumiam menor quantidade de medicamentos $(p=0,00)$, e apresentaram tendência a serem mais jovens $(p=0,06)$. Estas pacientes apresentaram, ainda, maiores valores de perfil lipídico (CT: $p=0,01 ; \mathrm{LDL}-\mathrm{C}$ : $p=0,02$ ). As queixas osteomusculares não se associaram à taxa de aderência ao medicamento. Conclusão: Os fatores associados à aderência de mulheres dislipidêmicas à prescrição médica de estatinas foram idade, quantidade de comorbidades e quantidade de medicamentos em uso.

\section{DESCRITORES}

Inibidores de Hidroximetilglutaril-CoA

Redutases

Dislipidemias

Perfil de saúde

Adesão à medicação

Saúde pública

\section{RESUMEN}

Objetivo: Identificar la tasa de adherencia al tratamiento con estatinas y los posibles factores relacionados en usuarias del Sistema Único de Salud. Métodos: Fueron evaluadas 71 mujeres (64,2 $\pm 11,0$ años) según nivel socioeconómico, comorbilidades, uso de medicamentos, nivel de actividad física, dolor muscular autoinformado, adherencia a la prescripción médica, composición corporal y perfil bioquímico. Los datos fueron analizados por frecuencia, test de chicuadrado y la prueba de Mann- Whitney $(p<0,05)$. Resultados: El 15,5\% de las mujeres no se adhirieron a la prescripción médica para el tratamiento con estatinas, éstas tenían menos comorbilidades $(p=0,01)$, consumían menos cantidad de medicamentos $(p=0,00)$ y presentaban tendencia a ser más jóvenes $(p=0,06)$. Además, estas pacientes presentaron valores mayores en el perfil lipídico (CT: $p=0,01, \mathrm{LDL}-\mathrm{C}: \mathrm{p}=0,02)$. La referencia de dolor musculoesquelético no se asociaron con la tasa de adherencia al medicamento. Conclusión: Los factores asociados con la adherencia de las mujeres con dislipidemia a la prescripción de estatinas fueron la edad, el número de comorbilidades y el número de medicamentos.

\section{DESCRIPTORES}

Inhibidores de Hidroximetilglutaril-CoA Reductasas

Dislipidemias

Perfil de salud

Cumplimiento de la medicación

Salud pública

${ }^{1}$ Doctoral student in Motricity Sciences, Universidade Estadual Paulista, Rio Claro, São Paulo, Brazil. mrb_unesp@yahoo.com.br 2 Master of Science in Motricity Sciences, Universidade Estadual Paulista, Bauru, São Paulo, Brazil. ${ }^{3}$ Bachelor in Physical Education, Universidade Estadual Paulista, Bauru, SP, Brazil. ${ }^{4}$ Doctor in Neurology/Neurosciences, Universidade Federal de São Paulo, São Paulo, SP, Brazil. ${ }^{5}$ Doctor in Sciences, Medical Physiology, Universidade de São Paulo, São Paulo, SP, Brazil. ${ }^{6}$ Doctor in Physical Education, Universidade Estadual de Campinas, Campinas, SP, Brazil. 


\section{INTRODUCTION}

Statins, also known as 3-Hidroxi-3-Metilglutaril coenzime A (HMG-CoA) reductase inhibitors, are efficient medication for the treatment of dyslipidemias, once they reduce 15 to $55 \%$ of low density lipoprotein levels (LDLC), 7 to $28 \%$ of triglycerides (TG), and elevate 2 to $10 \%$ of high density lipoprotein levels (HDL-C) $)^{(1-2)}$. In general, statins are well tolerated by most of patients and their toxic effects are specially related to the musculoskeletal system ${ }^{(3)}$. Myopathies related to statins affect 5 to $10 \%$ of patients ${ }^{(4)}$ and they can manifest by pains, cramps and muscle stiffness ${ }^{(5)}$, and strength reduction. Although the adverse effects, its efficacy and relative safety demonstrated by those medications made them be utilized worldwide ${ }^{(1)}$, staying between the most commercialized medication and a record in sales within the pharmaceutical industry in 2003.

However, studies show the variable adherence to the treatment, with rates identified between 30 and $40 \%{ }^{(7-9)}$, 50 and $70 \%^{(10)}$, reaching even $90 \%^{(11)}$. The factors influencing adherence of patients to statin treatment can be divided in three categories, known as: related to the patients (socio-economic status, comorbidities and adverse effects); to the physicians (application of guidelines recommendations and interaction with patients); and to the health system (cost and access to treatment) ${ }^{(12)}$. The difference of each assessed reality can contribute to its variability. In Brazil, there is lack of information regarding the treatment with statins in the Unified Health System (SUS).

Evidences indicate that guidelines for the treatment and prevention of dyslipidemias is being followed by SUS physicians, once it was found coherence within the Brazilian Society of Cardiology indications and the medical conducts for prescription and treatment follow-up in dyslipidemia situations ${ }^{(13)}$. It is also known that statins are free offered medications by the national public health system and, therefore, of easy access to the whole population. However, although the advances in relation to health actions and practices in the treatment of dyslipidemia, little is known about the rate and the determinant factors of adherence to the lipid-lowering medications within public health patients from national health.

Considering the high number of prescriptions of those medications, as well as its free distribution in public health services, the collection of those aspects is configured as high relevance for the design of more efficient strategies, in special for nursing professionals. In primary attention, nursing assistance are more frequent than medical consultations, leading to more contact of those professionals with patients; those factors contribute in a singular manner in the previous identification of medical treatment adherence and its adverse effects, as well as advices to patients. In light of the above, the present research aimed to identify the adherence rate to the lipid-lowering treatment with statins and possible related factors in female users from the Unified Health System in Bauru/SP.

\section{METHOD}

Research location: The present research was conducted in a Basic Healthcare Unit (UBS) in Bauru/SP. The city in question has 20 UBS distributed in urban areas, and the biggest unit was chosen for this study, localized in the central region. In this unit, the treatment prescription and follow-up of patients with dyslipidemia are done in accordance with the current guidelines, in which the medications are freely distributed by the Municipal Health Secretary ${ }^{(13)}$.

Ethical aspects: This study was approved by the Ethics in Research Committee from the Science Faculty of the São Paulo State University (UNESP) from Bauru (Protocol no 5252/2011), and all participants signed the Free and Informed Consent.

Patients recruitment: The screening of patients was done by cadastral surveys of active users of the unit with identification of dyslipidemia patients with the prescription of statins. This sorting was done from January to March, and from July to August, in 2012; in this study we selected only women, once they are more affected by adverse events ${ }^{(2,4-5)}$, as well as being those with less adherence to the treatment ${ }^{(11)}$.

From a universe of 22.465 active records, 195 female records were identified with statins prescription, from which name, date of birth and telephone number were collected. By telephone contact, the patients were invited to participate in the study, and two visits were scheduled for data collection with those who accepted to participate. At the end of the recruitment, it was verified 21 non-identified telephones, 11 patients not found, 37 denials, and 126 appointments scheduled; from those, 71 interviews were obtained, as indicated in Figure 1. All patients who did not come to the appointments were later rescheduled, totalizing 55 no-shows.

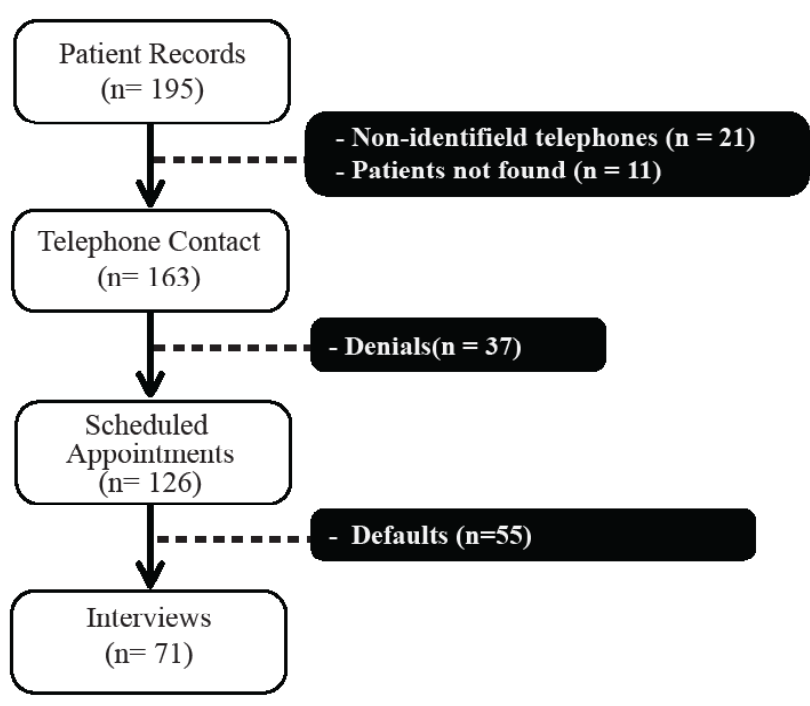

Figure 1 - Screening of participants from study
Adherence to statin treatment and associated factors in female users from the Unified Health System (SUS) Bonfim MR, Hansen A, Turi BC, Zanini GS, Oliveira ASB, Amaral SL, Monteiro HL 
Application of surveys: When participating in the study, patients answered to surveys related to socio-economic status, health condition, level of habitual physical activity, self-report of muscle pain and adherence to the treatment with statins. The socio-economic level was obtained by the Criteria for Economic Classification for Bra$\mathrm{zil}^{(14)}$, considering the classes A1, A2, B1, B2, C1, C2, D and E. For this research, we grouped the levels, being the patients classified as high ( $A$ and $B$ ), medium (C) and low (D and E) classes.

The health condition was obtained by anamnesis constituting in the identification of comorbidities and other current medications. For data analysis, the presence of the comorbidities arterial hypertension, type 2 diabetes and obesity was summed and categorized as i) 1 comorbidity and ii) 2 or more comorbidities, as well as the total count of current medications and its categories as i) up to 2 medications and ii) 3 or more current medications.

The level of habitual physical activity was obtained by the translated and validated Baecke ${ }^{(15)}$ questionnaire that determines physical activity in mobility, leisure and occupation domains. For data analysis we used raw values given by the point count of each domain proposed by the instrument, as well as the patient's classification as active or sedentary (<180 minutes of moderate or vigorous physical activity on the past six months).

The self-reported questionnaire for muscle pain was used to identify clinical signals referred to patients regarding statin effects on musculoskeletal system, as well as to obtain medicine treatment specificities. Once there is no validated questionnaire in the literature for this matter, we applied an adapted instrument ${ }^{(5)}$, to identify the characteristics of pain caused by statins, considering current and past complains. It is composed by open questions, binary or multiple choices, related to the location, beginning, and triggering or aggravating factors for muscle pain, as well as the treatment specificities (type of statins and doses in use, treatment period, use of other statins); those data was used to characterize the treatment of the patients, as well as to compare the characteristics of adherent and non-adherent patients.

The adherence to the treatment with statins was verified in two ways, as follows: i) medical prescription compliance and ii) adherence questionnaire application. The questionnaire chosen for this study ${ }^{(16)}$ was composed by the questions: 1) Do you forget to take the medication? 2) Do you take the medications at the indicated time? 3) When you are feeling fine, do you stop taking your medications? 4) If sometimes you don't feel well, do you stop taking your medications? We considered adherent those who were following the medical prescription, as well as those who answered no to the questions 1, 3 and 4, and positive to the question 2 ; the data was separately analyzed, in accordance with each instrument.
Body composition: To evaluate the nutritional status, we measured body weight and height to calculate the Body Mass Index $\left(\mathrm{BMI}=\right.$ weight $/$ height $\left.^{2}\right)$, adopting the cut-points established by the World Health Organization $^{(17)}$ to classify the patients as eutrophics ( $<25 \mathrm{Kg}$ / $\left.\mathrm{m}^{2}\right)$, overweight $\left(>25.1 \mathrm{Kg} / \mathrm{m}^{2}-\leq 29.9 \mathrm{Kg} / \mathrm{m}^{2}\right)$ and obese $\left(\geq 30 \mathrm{Kg} / \mathrm{m}^{2}\right)$. To assess the cardiovascular risk, the waist circumference (Cwaist) was measured in the medium point between the iliac crest and the last rib, using the anthropometric tape with precision in centimeters; its values was used as indicators for obesity $(>88 \mathrm{~cm})$ to quantify metabolic comorbidities, applying the criteria established by the metabolic syndrome guidelines ${ }^{(18)}$. The total lean body mass and body fat, as well as the percentage of fat, were obtained by dual energy $x$-ray absorptiometry (DXA), through total body scan (Hologic ${ }^{\circledR}$ ), following reference values in accordance with sex, age and ethnicity ${ }^{(19)}$.

Biochemical parameters: the biochemical parameters values were collected from medical records, collecting a maximal of three months retrospectively from the data collection. For statistical analysis, we used the raw data from total cholesterol (TC), high density lipoprotein (HDLc), low density lipoprotein (LDL-C), triglycerides (TG), creatine kinase (CK), alanine aminotransferase (ALT) and aspartate aminotransferase (AST), as well as its categories in normal or altered values ${ }^{(1)}$.

Statistical analysis: the obtained data was analyzed in accordance with the variable type (continuous or discrete), considering the interest categories from the presence/absence of specific characteristics, or groupings. The descriptive variables were presented as median and interquartile range (IQR), and analyzed by Mann Whitney test because of the absence of normal distribution. For categorical data analysis, absolute and relative frequency was done to identify characteristics from statin users, and the Chi-squared test to verify the existence of associations within the variables. All analysis were conducted with the SPSS 13.0 software for Windows, and a significance level of $\mathrm{p}<0.05$ was adopted.

\section{RESULTS}

The 71 dyslipidemic women with statin prescription that were interviewed were between 38 and 85 years $(64.2 \pm 11.0$ years), most of them older than 60 years (69\%). The studied patients were mostly classified as medium class (C - 48.6\%; A/B - 42.9\%; D/E - 8.6\%), overweight (42.3\%; weight: $69.6 \pm 12.3 \mathrm{Kg}$; IMC: $28.2 \pm 4.4 \mathrm{Kg} / \mathrm{m}^{2}$ ), with abdominal fat accumulation (56.5\%; Cwaist: $90.2 \pm 11.7$ $\mathrm{cm})$, with $33.8 \%$ of the sample with high percentage of body fat (\%BF: $40.5 \pm 4.9$ ); the predominance of sedentary lifestyle was observed in $71.8 \%$ of the cases.

Within the related morbidities, arterial hypertension was the most frequent $(74.6 \%)$, followed by abdominal obesity and type 2 diabetes (50.7\%), and the presence of 
two or more comorbidities was the most frequent condition (67.6\%; quantities of comorbidities: $1.82 \pm 0.9$ ). Regarding the medication treatment, $67.6 \%$ of patients used three or more medicines, and the values ranged from 0 to 10 different medicines ( $3.83 \pm 2.1$ medicines).

About the medical prescription fulfilment, $15.5 \%$ of women ( $n=11$ ) were not regularly using statins. The comparison of the analyzed parameters showed that the patients who did not follow medical prescriptions had less number of comorbidities $(p=0.01)$ and consumed less medications $(p=0.00)$ than those who followed the prescription, besides the tendency of being younger $(p=0.06)$. Those patients also presented higher values of TC $(p=0.01)$ and LDL-c $(p=0.02)$ (Table 1), with more occurrence of altered values for both variables (TC: $66.7 \%$ vs $34.5 \%$ e LDLc: $22.2 \%$ vs $9.1 \%)$.

Table 1 - Median and interquartile range (IQR) values of general characteristics from patients who followed or not the medical prescription for the use of statins - Bauru, SP, 2012

\begin{tabular}{|c|c|c|c|}
\hline \multirow[b]{2}{*}{ Variable } & \multicolumn{2}{|c|}{ Treatment with Statins } & \multirow[b]{2}{*}{ p-value } \\
\hline & $\begin{array}{c}\text { Interrupted } \\
(\mathrm{n}=11)\end{array}$ & Regular $(n=60)$ & \\
\hline Age (years) & $56.8(27.9)$ & $65.5(12.7)$ & 0.06 \\
\hline Socio-economic status & $23(9)$ & $20(9)$ & 0.53 \\
\hline Weight (Kg) & $60.7(12)$ & $68.6(14)$ & 0.16 \\
\hline Height (m) & $1.56(0.1)$ & $1.57(0.1)$ & 0.86 \\
\hline BMI $\left(\mathrm{Kg} / \mathrm{m}^{2}\right)$ & $27.0(5.9)$ & $28.2(6.7)$ & 0.25 \\
\hline Cwaist (cm) & $84.5(20)$ & 89.5 (14) & 0.14 \\
\hline Total Fat (g) & $22900(3763)$ & $28728(10693)$ & 0.14 \\
\hline Total Lean Mass (g) & $38764(9490)$ & 39994 (8216) & 0.68 \\
\hline \%Total Body Fat & $38.7(4.0)$ & $41.2(8.0)$ & 0.24 \\
\hline Quantity of Comorbidities & $1.0(2.0)$ & $2.0(2.0)$ & 0.01 \\
\hline Quantity of Medications & $2.0(1.0)$ & $4.0(3.0)$ & 0 \\
\hline Total Physical Activity & $8.0(1.7)$ & $8.1(2.4)$ & 0.67 \\
\hline Total Cholesterol (mg/dL) & $209(42)^{*}$ & $169\left(66^{*}\right.$ & 0.01 \\
\hline HDL-c (mg/dL) & $42(24)^{*}$ & $46(16)^{\S}$ & 0.87 \\
\hline LDL-c (mg/dL) & $128(37)^{*}$ & $97(52)^{\ddagger}$ & 0.02 \\
\hline Triglycerides (mg/dL) & $192(87)^{*}$ & $128(88)^{\ddagger}$ & 0.08 \\
\hline Creatine Kinase (U/L) & $116(132)^{\dagger}$ & $111(80)^{\#}$ & 0.44 \\
\hline $\operatorname{AST}(\mathrm{U} / \mathrm{L})$ & $23(12)^{*}$ & $22.5(11)^{* *}$ & 0.76 \\
\hline $\operatorname{ALT}(\mathbf{U} / \mathbf{L})$ & $22(20)^{*}$ & $18(9)^{\#}$ & 0.36 \\
\hline
\end{tabular}

Note: $\mathrm{BMI}=$ Body Mass Index; Cwaist = Waist Circumference; HDL-c: High Density Lipoprotein; LDL-c: Low Density Lipoprotein; AST: Aspartate Aminotransferase; ALT: Alanine Aminotransferase. ${ }^{*} n=09 ;{ }^{\dagger} n=08 ;{ }^{\ddagger} n=55$; $\S_{n}=54 ;{ }^{*} n=47 ;{ }^{* *} n=48$. Mann Whitney test.

Regarding the treatment with statins, we verified the administration of only two statin classes, predominantly simvastatin (90\%) over atorvastatin (10\%), generally prescribed in low doses (10mg 8.3\%, 20mg: 76.7\%, 30mg: $3.3 \%$ and $40 \mathrm{mg}: 11.7 \%)$. The mean time of medication use was $39.4 \pm 43.8$ months, varying from one to 240 months; during this period, more than $20 \%$ of the sample reported to use other statin class, trying to improve the treatment efficacy (41.7\%), as well as the side effects (33.3\%), or due to the facility to acquire the medicine $(25 \%)$.

About the treatment side effects, more specifically the presence of musculoskeletal discomforts, $53.3 \%$ of patients presented pain complaints and only $12.5 \%(n=4)$ were associated to the use of medication. The Chi-Square analysis demonstrated that the time of medication use $(p=0.06)$ and the physical activity $(p=0.02)$ were associated to generalized pain reports.

Table 2 presents the general characteristics from patients using statins who presented or not complaints of muscle pain. The Mann Whitney test identified significant differences on the level of physical activity and the characteristics of medication treatments; the users with complaints presented higher level of total physical activity $(p=0.03)$, besides the higher dose consumption $(p=0.05)$ for longer $(p=0.04)$.

Table 2 - Median and interquartile range (IQR) of general characteristics from patients in use of statins who presented or not complaints of muscle pain - Bauru, SP, 2012

\begin{tabular}{lccc}
\hline \multirow{2}{*}{\multicolumn{1}{c}{ Variable }} & \multicolumn{2}{c}{ Muscle Pain } & \\
\cline { 2 - 3 } & $\begin{array}{c}\text { Present } \\
(\mathbf{n}=\mathbf{3 2})\end{array}$ & $\begin{array}{c}\text { Absent } \\
(\mathbf{n}=\mathbf{2 8})\end{array}$ & p-value \\
\hline Statin Dose (mg/day) & $20(0)$ & $20(0)$ & $\mathbf{0 . 0 5}$ \\
Time of use (months) & $48(57)$ & $24(30)$ & $\mathbf{0 . 0 4}$ \\
Quantity of Comorbidities & $2.0(1.0)$ & $1.0(1.0)$ & 0.15 \\
Quantity of Medicines & $4.0(4.0)$ & $4.0(3.0)$ & 0.90 \\
Occupational Physical Activity & $2.6(0.8)$ & $2.5(0.6)$ & 0.44 \\
Leisure Physical Activity & $2.8(2.0)$ & $2.0(1.0)$ & $\mathbf{0 . 0 2}$ \\
Mobility Physical Activity & $3.0(1.4)$ & $2.6(1.5)$ & 0.35 \\
Total Physical Activity & $8.6(2.4)$ & $7.3(2.3)$ & $\mathbf{0 . 0 3}$ \\
Total Cholesterol (mg/dL) & $169.5(67)^{*}$ & $168(69)^{\S}$ & 0.87 \\
HDL-c (mg/dL) & $46.5(18)^{*}$ & $44(15)^{\ddagger}$ & 0.18 \\
LDL-c (mg/dL) & $97(55)^{*}$ & $95(43)^{\S}$ & 0.98 \\
Triglycerides (mg/dL) & $107(92)^{*}$ & $130(90)^{\S}$ & 0.31 \\
Creatine Kinase (U/L) & $86(77)^{\dagger}$ & $130(74)^{\sharp}$ & 0.07 \\
AST (U/L) & $21.5(11)^{\ddagger}$ & $23(10)^{*}$ & 0.47 \\
ALT (U/L) & $17(7)^{\dagger}$ & $20(10)^{* *}$ & 0.50 \\
\hline
\end{tabular}

Note: HDL-c: High Density Lipoprotein; LDL-c: Low Density Lipoprotein; AST: Aspartate Aminotransferase; ALT: Alanine Aminotransferase. ${ }^{*} n=28$; ${ }^{+} n=25 ;{ }^{\ddagger} n=26 ;{ }^{\circledR} n=27 ;{ }^{*} n=22 ;{ }^{* *} n=21$. Mann Whitney Test.

The obtained results in the adherence questionnaire demonstrated that $28.3 \%$ of patients were classified as non-adherent, and the forgetfulness was the most frequent factor $(25.0 \%)$ for non-adherence (Table 3$)$. The Chi-Squared test and the comparison tests showed absence of associations and significant differences in the studied variables between patients considered adherent or not by the instrument.
Adherence to statin treatment and associated factors in female users from the Unified Health System (SUS) Bonfim MR, Hansen A, Turi BC, Zanini GS, Oliveira ASB, Amaral SL, Monteiro HL 
Table 3 - Results from the questionnaire of adherence to treatment with statins of patients who are in use of medication - Bauru, SP, Brazil, 2012

\begin{tabular}{lcc}
\hline \multicolumn{1}{c}{ Questions } & Yes & No \\
\hline (1) Do you forget to take the medication? & $25.0 \%$ & $75.0 \%$ \\
$\begin{array}{l}\text { (2) Do you take the medications at the indicated } \\
\text { time? }\end{array}$ & $96.7 \%$ & $3.3 \%$ \\
$\begin{array}{l}\text { (3) When you are feeling fine, do you stop taking } \\
\text { your medications? }\end{array}$ & $1.7 \%$ & $98.3 \%$ \\
$\begin{array}{l}\text { (4) If sometimes you don't feel well, do you stop } \\
\text { taking your medications? }\end{array}$ & $5.0 \%$ & $95.0 \%$ \\
\hline Adherence to treatment & $\mathbf{7 1 . 7 \%}$ & $\mathbf{2 8 . 3 \%}$ \\
\hline
\end{tabular}

\section{DISCUSSION}

The data survey conducted in the UBS indicated that expressive portion of dyslipidemic patients suffered from other comorbidities, as arterial hypertension, type 2 diabetes and obesity. A previous study ${ }^{(20)}$ which evaluated a sample composed by 222 users from two UBS in Bauru, found $59.9 \%$ of patients had hypertension and diabetes, from those $31.5 \%$ also had high cholesterol levels, demonstrating the frequent presence of comorbidities in the studied population.

Similarly, in a recent data survey in 5 UBSs in Bauru with patients with the same age ${ }^{(21)}$, it was observed that from 963 assessed users, $76.8 \%$ had arterial hypertension, and the rate in women was $75.7 \%$. Besides that, $63 \%$ and $70 \%$ of users presented altered values of $\mathrm{BMI}$ and waist circumference, respectively, reaffirming the high occurrence of metabolic alterations in the attended population by the public health system in Bauru.

In accordance with the metabolic syndrome guidelines published by the Brazilian Society of Cardiology, the recommended strategies for the treatment of those disorders involve therapies with no drugs, through diets and physical activity, and drug treatment ${ }^{(22)}$. From the data obtained in this and the other researches cited above, the prescription of drug treatment is being broadly used in detriment of other strategies, considering the expressive quantity of administered medications, as well as the high occurrence of sedentary behavior presented by patients.

Regarding the treatment with statins, it was verified a tendency of younger patients, with less number of metabolic comorbidities and using less quantity of medicines to be less adherent to pharmacological medical prescription for dyslipidemia. These results are in accordance with previous studies which demonstrated that patients between 50 and 65 years are more adherent to the treatment with statins ${ }^{(23)}$, and in contiguous age groups lower levels of adherence are observed within older people and, predominantly, within the younger ones ${ }^{(7,11)}$. Besides that, it was verified that men are more adherent to the treatment with statins than women ${ }^{(7,11)}$, and the non-adherence is more present in patient with less ${ }^{(11)}$ or no ${ }^{(7)}$ comorbidity
In general, the non-adherence to the treatment with statins is a preoccupant reality, once it can be considered the main responsible to fail in attending the therapeutic goals ${ }^{(24)}$. In the present study it was verified that patients who did not follow the medical prescription were those who presented more altered lipid profile values, as well as the more elevated biochemical levels when compared to adherent patients. Besides that, it is important to highlight that all non-adherent patients to the medicine treatment were sedentary, indicating that no therapeutic strategy, including those without medications, were being done by them.

Insisting in the lipid-lowering treatment through statins is relevant, once it has been demonstrated that higher levels of adherence are associated with: i) lower medical costs related to the disease ${ }^{(25)}$; ii) reduction in the risk of development of coronary arterial disease ${ }^{(7,10)}$; and iii) decrease in the chance of hospitalization by myocardial infaction ${ }^{(8,25)}$. Within the patients who were in regular use of statin, it was verified a high adherence to treatment $(71.7 \%)$, and the main factor to classify them as non-adherent was the forgetfulness to use the medication.

Considering that only $5.0 \%$ of the sample reported to stop using the medication when they did not feel well, it can be suggested that experienced side effects by those patients presented low frequency, or they did not interfere in the treatment adherence. In the present study, it was also verified that, although more than half of patients referred muscle pain, only $12.5 \%$ related their pain with the use of statins, representing $6.7 \%$ of the total sample. The side effects rates observed in the present study are in agreement with those found in other studies, and varied from $5 \%^{(5)}$ to $10 \%{ }^{(26)}$.

In general, within the patients who reported presence of pain, it was verified that higher medication dose administration for longer, so as higher level of physical activity, were factors influencing the installation of this situation. Those aspects corroborate with the risk factors indicated by the literature as influencing the occurrence of muscle side effects by statins ${ }^{(1,5,26)}$. The fact of free available statins in the health system of the city to be restricted to simvastatin and atorvastatin, high to intermediate risk classes for the occurrence of muscle discomfort ${ }^{(5,27)}$ could have contributed to the occurrence of those side effects.

According to a recent publication ${ }^{(12)}$, the occurrence of side effects have been presented as a relevant factor which determines the low adherence to the treatment, being faced as a challenge for those patients who have it. A previous research ${ }^{(5)}$ demonstrated that $20 \%$ of patients who presented muscle symptoms due to the use of statins discontinued the use of the medication, an approximately $17 \%$ requested a reduction of doses. Similarly, a study ${ }^{(13)}$ verified that women in treatment with statins submitted to higher doses of medication had four times more chanc- 
es to present musculoskeletal complaints (Odds Ratio: 4.0 [1.04 - 15.38]), and its presence resulted in 6.4 times more chance to interrupt the drug treatment by themselves (Odds Ratio: 6.4 [1.53 - 26.78]).

Besides those evidences, in this research it was not identified an association between presence of pain (being generalized of specific due to the medication) and adherence to treatment, a behavior that was also observed for the other analyzed factors. Regarding the measure of adherence to statins, the major part of studies measure it indirectly ${ }^{(12)}$, and the count of pills, the control of medicaments taken away in pharmacies and the application of questionnaires can be used ${ }^{(12,28)}$. Although the low sensibility and accuracy, the questionnaires are well utilized due to its low cost and applicability in big populations ${ }^{(28)}$, being a quick and valid way to identify adherence to the treatment in clinical practice ${ }^{(24)}$. In Brazil, as well as in other countries, the Morisky-Green test have been broadly used to identify adherence to drug treatments ${ }^{(24,28)}$ and therefore, its adoption is recommended for future studies.

\section{REFERENCES}

1. Sociedade Brasileira de Cardiologia; Departamento de Aterosclerose. IV Diretrizes Brasileiras sobre Dislipidemias e Prevenção da Aterosclerose. Arq Bras Cardiol. 2007;88(1):2-19.

2. Pasternak RC, Smith SC Jr, Bairey-Merz CN, Grundy SM, Cleeman JI, Lefant C; American College of Cardiology; American Heart Association; National Heart, Lung and Blood Institute. ACC/AHA/NHLBI clinical advisory on the use and safety of statins. J Am Coll Cardiol. 2002;40(3):567-72.

3. Brown WV. Safety of statins. Curr Opin Lipidol. 2008;19(6):558-62.

4. Joy TR, Hegele RA. Narrative review: statin-related myopathy. Ann Inter Med. 2009;150(12):858-68.

5. Bruckert E, Hayem G, Dejager S, Yau C, Bégaud B. Mild to moderate muscular symptoms with high dosage statin therapy in hyperlipidemic patients - the PRIMO study. Cardiovasc Drugs Ther. 2005;19(6):403-14.

6. Krishnan GM, Thompson PD. The effects of statins on skeletal muscle strength and exercise performance. Curr Opin Lipidol. 2010;21(4):324-8.

7. Degli Esposti L, Saragoni S, Batacchi P, Benemei S, Geppetti $P$, Sturani A, et al. Adherence to statin treatment and health outcomes in an Italian cohort of newly treated patients: results from an administrative database analysis. Clin Ther. 2012;34(1):190-9.
In the present study it was verified that younger women who presented few comorbidities and use low quantity of medications are less likely to adhere to medical prescription of pharmacological treatment with statins in the public health system. These data indicates the need of public health professionals, as nurses, physicians, nutritionists, within others, to implement strategies for the awareness of this specific public, aiming the increase in adherence to treatment with statins and a more rigorous follow-up of the lipid profile, besides the expansion of the stimulus for nondrugs therapeutic adoption measures in the public services, especially for younger women with dyslipidemia.

\section{CONCLUSION}

The non-compliance of medical prescription for regular use of statins between women users of the Unified Health System was $15.5 \%$, and the associated factors to the non-adherence to the drug treatment were age, lower presence of comorbidities and lower consumption of medications.

8. Penning-van Beest FJ, Termorshuizen F, Goettsch WG, Klungel $\mathrm{OH}$, Kastelein JJ, Herings RMC. Adherence to evidence-based statin guidelines reduces the risk of hospitalizations for acute myocardial infarction by $40 \%$ : a cohort study. Eur Heart J. 2007;28(2):154-9.

9. Chan DC, Shrank WH, Cutler D, Jan S, Fischer MA, Jun Liu BS, et al. Patient, physician and payment predictors of statin adherence. Med Care. 2010;48(3):196-202.

10. Perreault S, Dragomir A, Blais L, Bérard A, Lalonde L, White M, et al. Eur J Clin Pharmacol. 2009;65(10):1013-24.

11. Wong MCS, Jiang JY, Griffiths SM. Adherence to lipid-lowering agents among 11.042 patients in clinical practice. Int J Clin Pract. 2011;65(7):741-8.

12. Mauskop A, Borden WB. Predictors of statin adherence. Curr Cardiol Rep. 2011;13(6):553-8.

13. Bonfim MR, Oliveira ASB, Amaral SL, Monteiro HL. Caracterização do tratamento medicamentoso com estatinas em unidade básica de saúde. Medicina (Ribeirão Preto). 2013;46(1):47-55.

14. Associação Brasileira de Empresas de Pesquisa. Critério de classificação econômica Brasil [Internet]. 2009 [citado 2013 nov. 21]. Disponível em: http://www.abep.org/new/

15. Florindo AA, Latorre MA. Validation and reliability of the Baecke questionnaire for the evaluation of habitual physical activity in adult men. Rev Bras Med Esporte [Internet]. 2003 [cited 2013 Nov 22];9(3):129-35. Available from: http://www.scielo. $\mathrm{br} / \mathrm{pdf} / \mathrm{rbme} / \mathrm{v9n3} / 17261 . \mathrm{pdf}$
Adherence to statin treatment and associated factors in female users from the Unified Health System (SUS) Bonfim MR, Hansen A, Turi BC, Zanini GS, Oliveira ASB, Amaral SL, Monteiro HL 
16. Morisky DE, Green LW, Levine AM. Concurrent and predictive validity of a self-reported measure of medication adherence. Med Care. 1986;24(1):67-74.

17. World Health Organization. Obesity, preventing and managing the global epidemic: report of the WHO Consultation on Obesity [Internet]. Geneva; 1998. [cited 2013 Nov 2]. Available from: http://www.who.int/nutrition/publications/ obesity_executive_summary.pdf

18. World Health Organization. Waist circumference and waisthip ratio: report of a WHO Expert Consultation [Internet]. Geneva; 2008 [cited 2013 Nov 22]. Available from: http:// whqlibdoc.who.int/publications/2011/9789241501491_ eng.pdf

19. Kelly TL, Wilson KE, Heymsfield SB. Dual energy X-Ray absorptiometry body composition reference values from NHANES. PLoS ONE. 2009;4(9):e7038.

20. Turi BC, Codogno JS, Fernandes RA, Monteiro HL. Associação entre doenças crônicas em adultos e redução dos níveis de atividade física. Medicina (Ribeirão Preto). 2011;44(4):389-95.

21. Turi BC, Codogno JS, Fernandes RA, Monteiro HL. Prática de atividade física, adiposidade corporal e hipertensão em usuários do SUS. Rev Bras Epidemiol. 2014. No prelo.

22. Sociedade Brasileira de Hipertensão; Sociedade Brasileira de Cardiologia; Sociedade Brasileira de Endocrinologia e Metabologia; Sociedade Brasileira de Diabetes. I Diretriz Brasileira de Diagnóstico e Tratamento da Síndrome Metabólica. Arq Bras Cardiol. 2005;84 Supl. 1:3-28.
23. Mann DM, Woodward M, Muntner P, Falzon L, Kronish I. Predictors of nonadherence to statins: a systematic review and meta-analysis. Ann Pharmacother. 2010;44(9):1410-21.

24. Bermingham M, Hayden J, Dawkins I, Miwa S, Gibson D, McDonald K, et al. Prospective analysis of LDL-c goal achievement and self-reported medication adherence among statin users in primary care. Clin Ther. 2011;33(9):1180-9.

25. Sokol MC, McGuigan KA, Verbrugge RR, Epstein RS. Impact of medication adherence on hospitalization risk and healthcare cost. Med Care. 2005;43(6):521-30.

26. Thompson PD, Clarkson PM, Rosenson RS. An assessment of statin safety by muscle experts. Am J Cardiol. 2006;97(8A):69C-76C.

27. Rallidis LS, Fountoulaki K, Anastasiou-Nana M. Managing the underestimated risk of statin-associated myopathy. Int J Cardiol. 2012;159(3):169-76.

28. Ben AJ, Neuman CR, Mengue SS. The Brief Medication Questionnaire and Morisky-Green test to evaluate medication adherence. Rev Saúde Pública. 2012;46(2):279-89. 